Eur. J. Clin. Chem. Clin. Biochem.

Vol. 32, 1994, pp. 361-364

(c) 1994 Walter de Gruyter \& Co.

Berlin $\cdot$ New York

\title{
Influence of Uraemia on the Determination of Blood Glycohaemoglobin by HPLC, Electrophoresis and Affinity Chromatography in Diabetic and Non-Diabetic Patients
}

\author{
By M. H. Herruer ${ }^{1}$, E. A. W. van Kooten ${ }^{1}$, H. E. Sluiter ${ }^{2}$ and F. M. J. Zuijderhoudt ${ }^{1}$ \\ 1 Department of Clinical Chemistry \\ 2 Department of Internal Medicine, Stichting Deventer Ziekenhuizen, Deventer; The Netherlands
}

(Received November 5, 1993/February 14, 1994)

Summary: Glycohaemoglobin in human blood can be determined by several methods. We investigated three methods used in daily practice, viz. affinity chromatography, HPLC and electrophoresis. We examined the influence of uraemia in diabetic and non-diabetic patients on the results obtained with HPLC and electrophoresis and compared these with the results obtained with affinity chromatography. Our current method (electrophoresis) proved to be very sensitive to uraemia giving falsely elevated levels of $\mathrm{HbA}_{1}$. HPLC was not disturbed by uraemia.

\section{Introduction}

During the last decade the measurement of glycohaemoglobin has proven to be a useful tool in glycaemic control (1). Glycohaemoglobin is formed by a non-enzymatic reaction between glucose or other carbohydrates and haemoglobin. For example, the main haemoglobin, $\mathrm{HbA}_{0}$, is glycated at the $\mathrm{N}$-terminal valine ( $\alpha$-chain $14 \%, \beta$-chain $60 \%$ ) or at an $\varepsilon$-lysine residue ( $\alpha$-chain $40 \%, \beta$-chain $46 \%$ ) to form $\mathrm{HbA}_{1 \mathrm{a} 1}, \mathrm{HbA}_{1 \mathrm{a} 2}, \mathrm{HbA}_{1 \mathrm{~b}}$ and $\mathrm{HbA}_{1 \mathrm{c}}$ respectively. Together these compounds are known as $\mathrm{HbA}_{1}$ (1).

Glycohaemoglobin in blood is commonly determined by HPLC, electrophoresis or affinity chromatography $(2-4)$.

In the HPLC method, different haemoglobins are bound to a cation-exchange column, and the $\mathrm{HbA}_{1 \mathrm{c}}$ fraction is quantitated. Affinity chromatography is based on the binding of all glycated haemoglobins to phenylboronate coupled to agarose.

Electrophoresis separates $\mathrm{HbA}_{1}$ from other haemoglobins by electroendosmosis.
Unfortunately, interference by alcohol, acetaldehyde, lipaemia and uraemia is very common $(3-5)$. Uraemia is particularly common in diabetes. Interference from uraemia can be explained by carbamylation of haemoglobin. This carbamylated haemoglobin comigrates with $\mathrm{HbA}_{1 \mathrm{c}}$ in HPLC and electrophoresis thus leading to an overestimation of the result (6-7).

Uraemia has been reported as an interfering factor in HPLC results from diabetic population (8). Recently, Tsang et al. reported that the Ciba Corning electroendosmosis is not affected by uraemia (plasma urea $>25$ mmol/l) in diabetic patients (9). Since affinity chromatography is based essentially on binding of the carbohydrate moiety of the protein to the resin, this technique is theoretically not affected by carbamylation (2). In this study we investigated the influence of uraemia on the results obtained by HPLC and electrophoresis, compared with the results obtained with affinity chromatography.

\section{Materials and Methods}

Samples

Blood was drawn in $5 \mathrm{ml}$ EDTA tubes. After centrifugation at $3000 \mathrm{~g}$ for $10 \mathrm{~min}$, plasma was removed and used for urca determi- 
nation. Red blood cells were washed with $9 \mathrm{~g} / \mathrm{l} \mathrm{NaCl}$ and used for measurement of $\mathrm{HbA}_{1}$, total glycated $\mathrm{Hb}$ and $\mathrm{HbA}_{1 \mathrm{c}}$.

\section{Electrophoresis}

After an overnight incubation in $9 \mathrm{~g} / 1 \mathrm{NaCl}$, cells were sedimented by centrifugation $(10 \mathrm{~min}, 4000 \mathrm{~g}$ ) and $100 \mu \mathrm{l}$ of pelleted cells were added to $800 \mu$ l of water. The haemolysate was kept overnight at $-20^{\circ} \mathrm{C}$, then $0.8 \mu \mathrm{l}$ was spotted on agar gels (Ciba Corning Diagnostics N. V., Houten, NL). After electrophoresis in "glycohaemoglobin buffer" pH 6.3 (Ciba Corning Diagnostics N. V., Houten, NL), gels were stained with Amido Black and scanned with a Cliniscan densitometer (Helena Laboratories, Gateshead, UK).

\section{Affinity chromatography}

An aliquot of pelleted cells $(50 \mu \mathrm{l})$ was added to $1 \mathrm{ml}$ of glycohaemolysis II (Instruchemie Hilversum B. V., NL). After centrifugation at $3000 \mathrm{~g}$ for $5 \mathrm{~min}, 50 \mu \mathrm{l}$ of the haemolysate were placed on a Glyco.gel II column (Pierce Chemical Company, USA) and eluted as described by the manufacturer.

\section{High performance liquid chromatography}

EDTA-blood $(0.6 \mathrm{ml})$ was mixed with $10 \mathrm{ml} 9 \mathrm{~g} / \mathrm{l}$ saline and incubated for 4 hours at $37^{\circ} \mathrm{C}$. Cells were sedimented by centrifugation at $3000 \mathrm{~g}$ for $5 \mathrm{~min}$. Water $(2.5 \mathrm{ml})$ and $\mathrm{CCl}_{4}(0.5 \mathrm{ml})$ were added to resulting pellet of red cells, and the mixture vigorously shaken for $2 \mathrm{~min}$. After centrifugation, $70 \mu \mathrm{l}$ of the haemolysate were added to $700 \mu \mathrm{l}$ of "sample buffer". Samples were placed on a Mono$\mathrm{S}$ HR5/5 column and eluted using a salt gradient $(0-0.3 \mathrm{~mol} / \mathrm{l}$ $\mathrm{NaCl}$ ) in $0.01 \mathrm{~mol} / 1$ malonic acid $\mathrm{pH} 5.7$. This procedure separates $\mathrm{HbF}$ from $\mathrm{HbA}_{1 \mathrm{c}}$ (Pharmacia, Uppsala, Sweden).

Urea was measured with urease (Boehringer Mannheim $\mathrm{GmbH}$, Germany) on a Hitachi 717 (Hitachi Ltd. Tokyo, Japan).

\section{Within-run precision}

Two pools of haemolysate were prepared for each method and measured 14 times in the same run.

The coefficients of variation for electrophoresis (5-9\%) were two to three times higher than for the other method.

\section{Between-run precision}

Two control sera from Instruchemie (Glycohemonorm and Glycohemopath) were used for HPLC and affinity chromatography. Two haemolysates of Ciba Corning (high $\mathrm{HbA}_{1}$ and low $\mathrm{HbA}_{1}$ ) were used for electrophoresis. The controls were measured 10 times during a period of 3 months.

The coefficients of variation for electrophoresis $(10-12 \%)$ were two to three times higher than for the other methods.

\section{Accuracy}

Freeze dried haemolysates, which are routinely used for external quality control in hospital laboratories in the Netherlands, were obtained from the SKZL (Dutch Foundation for Quality Assessment in Clinical Chemistry). Values were compared with the average values obtained by all participants using the same method.

In all three methods our values ranged between the highest and lowest value found by all participants.

\section{Patient selection}

To determine the interference by urea, the following patient groups were selected:

healthy volunteers, non-diabetic, non-uraemic, age 20-60 (group $1, \mathrm{n}=24$ );

non-diabetic, uraemic patients receiving haemodialysis, age 3479 (group 2, $\mathrm{n}=20$ );

diabetic, non-uraemic patients, age $17-76$ (group $3, n=25$ ) and

diabetic, uraemic patients receiving haemodialysis, age 35-71 (group 4, $n=16$ ).

Non-uraemic patients had blood urea concentrations between 3 and $7 \mathrm{mmol} / \mathrm{l}$. Blood urea concentrations in uraemic patients were $>18$ $\mathrm{mmol} / \mathrm{l}$ for at least three months preceding this investigation. The mean urea concentration of group 2 patients was $29.4 \mathrm{mmol} / \mathrm{l}$, and of group 4 patients $28.5 \mathrm{mmol} / \mathrm{l}$.

\section{Statistics}

We used Student's t-test (unpaired data) for determining the significance of the influence of uraemia on the various methods.

\section{Results}

Interference in HPLC and electrophoresis by uraemia was investigated using the 3 groups of patients and one group of healthy volunteers. The results are shown in table 1.

We assumed that the results of glycohaemoglobin measurements by affinity chromatography would not be disturbed by excessive amounts of carbamylated haemoglobin. The hypothesis that $\mathrm{HbA}_{1(\mathrm{c})}$ measurements by HPLC and electrophoresis are unreliable when uraemia is present was tested by determining the differences between the three methods in four groups of subjects as described in Materials and Methods. We calculated the differences between the values for affinity chromatography $(\mathrm{A})$ and HPLC $(\mathrm{H})$, or affinity chromatography and electrophoresis $(E)$ for all persons in each group $(\triangle H A$ and $\triangle \mathrm{EA}$ ). Next we used Student's t-test for unpaired data to compare $\triangle \mathrm{HA}$ and $\triangle \mathrm{EA}$ of uraemic and nonuraemic subjects. A significant difference was found between affinity chromatography and electrophoresis, but not between affinity chromatography and HPLC.

These findings are in accord with the relation between the urea concentration and the results of glycohaemoglobin measurements in group 1 volunteers and group 2 uraemic patients as shown in figure 1 . Affinity chromatography gives essentially the same results in both groups, whereas electrophoresis gives considerably higher results in the uraemic group. The same phenomenon is harder to assess in diabetic patients, becauise of the higher glycohaemoglobin values and the wide range of results in these groups.

The values for glycated haemoglobins in group 1 volunteers (fig. 1) show different rieference values for each 
Tab. 1 Interference of carbamylated haemoglobin with the measurement of glycohaemoglobin using three different methods, one group of healthy volunteers and three groups of patients.

$\triangle H A$ : difference between HPLC and affinity chromatography in each group:

$\triangle E A$ : difference between electrophoresis and affinity chromatography in each group.

\begin{tabular}{|c|c|c|c|c|c|c|}
\hline & $\mathbf{N}$ & $\begin{array}{l}\text { Affinity } \\
\text { chromatography } \\
\text { Mean (SD) }\end{array}$ & Mean $\triangle \mathrm{HA}$ & $\begin{array}{l}\text { HPLC } \\
\text { Mean (SD) }\end{array}$ & Mean $\triangle \mathrm{EA}$ & $\begin{array}{l}\text { Electrophoresis } \\
\text { Mean (SD) }\end{array}$ \\
\hline $\begin{array}{l}\text { Group } 1 \\
\text { Healthy }\end{array}$ & 24 & $4.2(0.5)$ & 0.8 & $5.0(0.4)$ & 2.6 & $6.8(1.1)$ \\
\hline $\begin{array}{l}\text { Group } 2 \\
\text { Uraemic }\end{array}$ & 20 & $4.6(0.5)$ & 1.8 & $6.4(0.6)$ & 5.2 & $9.8(1.4)$ \\
\hline $\begin{array}{l}\text { Group } 3 \\
\text { Diabetic }\end{array}$ & 25 & $8.8(2.6)$ & 0.1 & $8.9(1.8)$ & 2.1 & $10.9(2.4)$ \\
\hline $\begin{array}{l}\text { Group } 4 \\
\text { Uraemic diabetic }\end{array}$ & 16 & $7.2(2.5)$ & 0.5 & $7.7(1.4)$ & 3.6 & $10.8(2.5)$ \\
\hline
\end{tabular}

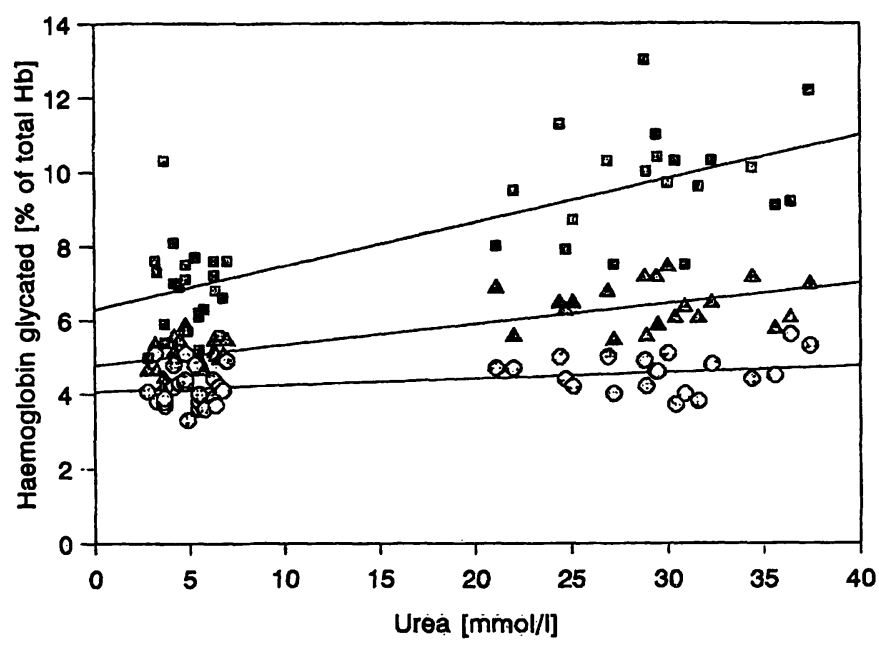

Fig. 1 Influence of uraemia on the measurement of glycohaemoglobin in healthy volunteers and patients with normal glucose metabolism (group 1 and group 2).

$\square=$ Electrophoresis

$\Delta=$ HPLC

$O=$ Affinity chromatography

Values for the linear regression lines are respectively

$y=0.12 x+6.3$

$y=0.06 x+4.8$

$y=0.02 x+4.1$

$y=$ haemoglobin glycated (\% of total haemoglobin).

$\mathrm{x}=$ urea $(\mathrm{mmol} / \mathrm{l})$

of the three methods. Different reference values can be expected because the three methods are not based on corresponding principles of measurement, so that the actual fraction of glycated haemoglobins is different for each method.

\section{Discussion}

Our objective was to investigate interference by carbamylated haemoglobin in glycohaemoglobin measure-
The difference in $\triangle \mathrm{HA}$ between group 1 and 2 is not significant $(p>0.05)$ whereas the difference in $\triangle E A$ is $(p<0.001)$.

The difference in $\triangle H A$ between group 3 and 4 is not significant $(p>0.05)$, whereas the difference in $\triangle E A$ is $(p<0.001)$. 
ent levels of glycohaemoglobin as measured with affinity chromatography $(8.8$ vs $7.2 \% \mathrm{p}<0.01)$. In our study, the HPLC results show no significant differences from the affinity chromatography results for diabetic patients with $(7.2$ vs $7.7 \% \mathrm{p}>0.05)$ and without $(8.8$ vs $8.9 \% \mathrm{p}>0.05$ ) uraemia. Our results confirm that carbamylated haemoglobin comigrates with glycohaemoglobin in electrophoresis. In contrast, and unex- pectedly, the measurement of $\mathrm{HbA}_{1}$ by HPLC was not disturbed by the presence of uraemia, and can therefore be used for monitoring the glycaemia fo diabetic patients with uraemia.

\section{Acknowledgement}

The authors thank Mr. H.J.M. Salden for his helpful suggestions regarding the preparation of this manuscript.

\section{References}

1. Baynes, J. W., Bunn, H. F., Goldstein, D., Harris, M., Martin, D. B., Peterson, C. \& Winterhalter, K. (1984) National Diabetes Data. Group: Report on the expert committee on glycosylated hemoglobin. Diabetes Care 7, 602-606.

2. Bruns, D. E. (1984) Specific Affinity-chromatographic measurement of glycated hemoglobins in uremic patients. Clin. Chem. 30, 569-571.

3. Klenk, D. C. (1982) Determinations of glycosylated hemoglobin by affinity-chromatography: Comparison with colorimetric and ion-exchange methods and effects of common interferences. Clin. Chem. 28, 2088-2094.

4. Kortlandt, W., Van Rijn, H. J. M., Hoeke, J. O. O. \& Thijssen, J. H. H. (1983) Comparison of three different assay procedures for the determination of $\mathrm{HbAl}$ with special attention to the influence of pre-HbAlc, temperature and haemoglobin concentration. Ann. Clin. Biochem. 22, 261-268.

5. Yatscoff, R. W., Tevaarwerk, G. J. M., Clarson, C. L. \& Warnock, L. M. (1983) Interference of fetal hemoglobin and labile glycosylated hemoglobin with measurements of glycosylated hemoglobin. Clin. Chem. 29, 543-545.

6. Flückiger, R., Harmon, W., Meier, W., Loo, S. \& Gabbay, K H. (1981) Hemoglobin carbamylation in uremia. New Engl. J. Med. 304, 823-827.

7. Tesio, F., Cecchin, E., De Marchi, S. \& Quala, P. (1982) Glycosylated or carbamylated hemoglobin in uremia. New Engl. J. Med. 306, 1053.

8. Engbaek, F., Christensen, S. E. \& Jespersen, B. (1989) Enżyme immunoassay of hemoglobin A1c: Analytical characteristics and clinical performance for patients with diabetes mellitus, with and without uremia. Clin. Chem. 35, 93-97.

9. Tsang, W. M., Priyakumar, P. \& Grenfell, A. (1991) Glycated haemoglobin measurement in uraemic patients. Ann. Clin. Biochem. 28, 414-416.

Dr F. M. J. Żuijderhoudt Department of Clinical Chemistry Stichting Deventer Ziekenhuizen $\mathrm{H} \mathrm{J} \mathrm{Ph}$ Fesevurstraat 7 NL-7415 CM Deventer The Netherlands 